\title{
Whole-body cryostimulation as an effective method of reducing low-grade inflammation in obese men
}

\author{
Ewa Ziemann · Robert A. Olek • Tomasz Grzywacz • \\ Jędrzej Antosiewicz • Sylwester Kujach • Marcin Luszczyk • \\ Mirosław Smaruj $\cdot$ Ewelina Śledziewska $\cdot$ Radosław Laskowski
}

Received: 7 March 2013/ Accepted: 11 May 2013/Published online: 7 June 2013

(c) The Author(s) 2013. This article is published with open access at Springerlink.com

\begin{abstract}
This study was aimed to evaluate anti-inflammatory effect of the whole body cryostimulation in obese men. Fourteen subjects (BMI $>30 \mathrm{~kg} \mathrm{~m}^{-2}$ ), divided into two subgroups according to cardiorespiratory fitness: higher (HCF) or lower (LCF), have been exposed to 10 sessions in a cryogenic chamber $\left(-110{ }^{\circ} \mathrm{C}\right)$. Blood samples were collected before, $30 \mathrm{~min}$ and $24 \mathrm{~h}$ after the first, fifth and last cryostimulation. Coldness exposures affected blood cytokine profile; however, the response depended on subjects' fitness capacity. Concentrations of pro-inflammatory cytokines in the LCF decreased by $19,6.8$, and $7.4 \%$ in IL-6, resistin, and visfatin, respectively. TNF $\alpha$ in the LCF dropped 4.3-fold compared to baseline, while in the HCF, changes were smaller, yet significant. Antiinflammatory cytokine IL-10 increased in both groups. No changes in adiponectin and leptin were observed in either
\end{abstract}

E. Ziemann $(\bowtie) \cdot$ T. Grzywacz · S. Kujach · M. Łuszczyk ·

E. Śledziewska $\cdot$ R. Laskowski

Department of Physiology, Gdansk University of Physical

Education and Sport, Kazimierza Górskiego 1, 80-336 Gdansk,

Poland

e-mail: ewann@awf.gda.pl

R. A. Olek

Department of Biochemistry, Gdansk University of Physical Education and Sport, Kazimierza Górskiego 1, 80-336 Gdansk, Poland

J. Antosiewicz

Department of Sport Psychology, Warsaw School of Social

Sciences and Humanities, Warsaw, Chodakowska 19/31,

03-815 Warszawa, Poland

M. Smaruj

Department of the Theory of Sport, Gdansk University of Physical Education and Sport, Kazimierza Górskiego 1, 80-336 Gdansk, Poland group. Obtained results suggest that whole body cryostimulation can be a supplementary method for obese in reducing systemic inflammation.

Keywords Adipocytokines - Cold exposure - Visceral fat tissue $\cdot$ Muscle mass

\section{Introduction}

Recent reports on obesity have shown an increasing prevalence of this condition since the 1990s, which is also predicted to grow even further in European populations by 2015 [1]. Adipose tissue is the important, regulatory factor of many pathological processes that accompany obesity [2]. Certain cytokines produced by this tissue are thought to provide an important link between obesity, insulin resistance, and related inflammatory disorders [3, 4]. Moreover, in obese individuals, adipose tissue contains a large number of macrophages, which are the source of TNF $\alpha$, IL- 6 and other cytokines [5]. Circulating cytokines regulate energy homeostasis, neuroendocrine, and immune functions; however, the presence of an excessive amount of fat tissue and resulting, increased level of some pro-inflammatory cytokines have been observed to lead to low-grade systemic inflammation in obese individuals $[2,6,7]$.

Physical exercise is one of the mechanisms that may be responsible for the anti-inflammatory response and protection against chronic medical disorders associated with low-grade inflammation [8]. During exercise, skeletal muscles produce and release myokines, which may induce the anti-inflammatory effect and act as energy sensors, exerting both local and endocrine metabolic agents [9]. Furthermore, some of these myokines might change the metabolism of white fat tissue [10]. Data on physical 
exercise characteristics (type, duration, and intensity) ensuring an effective reduction in inflammation markers have not yet been obtained [11, 12]. Aerobic exercise combined with resistance exercise has been shown to have a greater anti-inflammatory effect than each separately [13]. Nonetheless, some studies have presented inconsistent findings regarding the anti-inflammatory effect of exercise [14]. In several studies, exercise did not trigger any declines in the levels of pro-inflammatory cytokines TNF $\alpha$, IL-1 $\beta$, and CRP [14-16]. In addition to exercise, diet and medically-induced weight loss have been previously shown to attenuate inflammation [17, 18] and to promote lipid utilization in skeletal muscle in obese people [19]. Regardless, some studies have reported that these treatments cause weight loss only, without reducing the inflammatory state. For example, CRP and IL-6 were shown to drop in morbidly obese patients as a result of a bariatric surgery; however, changes in $\mathrm{TNF} \alpha$ were not equivocal [20]. Furthermore, a $25 \%$ calorie restriction in diet in conjunction with an aerobic training-induced weight loss did not impact markers of systemic inflammation or expression of inflammation-related adipose genes in overweight individuals [21]. Overall, high demand for effective, complementary methods for reducing systemic low-grade inflammation is highly justified.

Whole-body cryostimulation may be an alternative method for reducing inflammation [22-24]. It has been shown to reduce pro-inflammatory response, relieve pain more effectively than other local cryotherapies and enhance muscles' post-exercise recovery $[25,26]$. What is more, whole-body cryostimulation caused changes in the cytokine profile in healthy men. Twenty sessions of this treatment resulted in an increase of the anti-inflammatory cytokine IL-10 and pleiotropic cytokine IL-6 and a decrease of pro-inflammatory IL-1 $\alpha$ [27]. Additionally, other cold treatments induced changes in the cytokine levels of adipose tissue, adiponectin, resistin, and leptin [28, 29]; however, the applied temperatures were far from the extreme temperature used in whole-body cryostimulation.

To our knowledge, no studies have so far investigated the effect of whole-body cryostimulation on the secretion of hormones and cytokines in obese individuals. Thus, the present study was designed to evaluate the effects of whole-body cryostimulation in two stages. First, we determined the influence of physical cardiorespiratory fitness capacity on the concentration of adipocytokines in obese men. Second, we assessed the effects of whole-body cryostimulation on adipocytokines in two groups of obese men characterised by either higher (HCF) or lower fitness capacity (LCF). Basing on previous investigations, our primary hypothesis assumed that whole-body cryostimulation would reduce low-grade systemic inflammation in obese men and induce significant growth in the antiinflammatory cytokine level. Finally, we verified whether and how the immunological response depended on subjects' cardiorespiratory capacity fitness.

\section{Methods}

\section{Subjects}

Fourteen obese men participated in the experiment $(40 \pm 4.0$ years of age, height of $178 \pm 3.0 \mathrm{~cm}$, HCF weight of $99.8 \pm 4.6 \mathrm{~kg}$, and LCF weight of $107.5 \pm$ $12.1 \mathrm{~kg}$ ). They were recruited via an advertisement placed in a local newspaper. All the subjects underwent a medical check-up before the exercise test and being submitted to cold exposure. Those with uncontrolled hypertension (diastolic blood pressure over $100 \mathrm{~mm} \mathrm{Hg}$ ), a history of cardiac arrhythmia, cardio-respiratory disorders, and cold allergy were excluded from the study. The participants were categorised as obese based on their BMI according to the current guidelines $\left(\mathrm{BMI}>30 \mathrm{~kg} \mathrm{~m}^{-2}\right.$ ) [30]. All patients were medication-free. The participants had never previously been subjected to any form of cryotherapy. Written, informed consent was obtained from all subjects. All procedures were approved by the Bioethical Committee of the Regional Medical Society in Gdansk NKEBN/245/2009 and conformed to the standards set by the Declaration of Helsinki.

One week prior to the start of the experiment, body composition and aerobic capacity were determined for each participant. The group was divided into two subgroups according to the participants' cardiorespiratory fitness, which had been measured in terms of the maximal oxygen consumption $\left(\mathrm{VO}_{2 \max }\right)$. Based on the classification proposed by Astrand [31], subjects with $\mathrm{VO}_{2 \max }$ above $35 \mathrm{~mL} \mathrm{~kg}^{-1} \mathrm{~min}^{-1}$ were assigned to the HCF group, whereas those with the lower $\mathrm{VO}_{2 \max }$ were enrolled in the LCF group. The HCF group (via a verbal survey) described its regular, long-term physical activity as 3-4 h per week of aerobic exercise with moderate intensity, including some resistance drills. During the experiment, all participants were instructed not to change any aspect of their daily habits regarding, e.g., diet. However, to explicitly assess the effect of cryostimulation on cytokine concentration, subjects were asked to avoid any form of exercise or other medical treatment. The schedule of the experiment is presented in Fig. 1.

Body composition assessment

Body mass (BM) and body composition were estimated using a multi-frequency impedance plethysmograph body 
Fig. 1 The study design

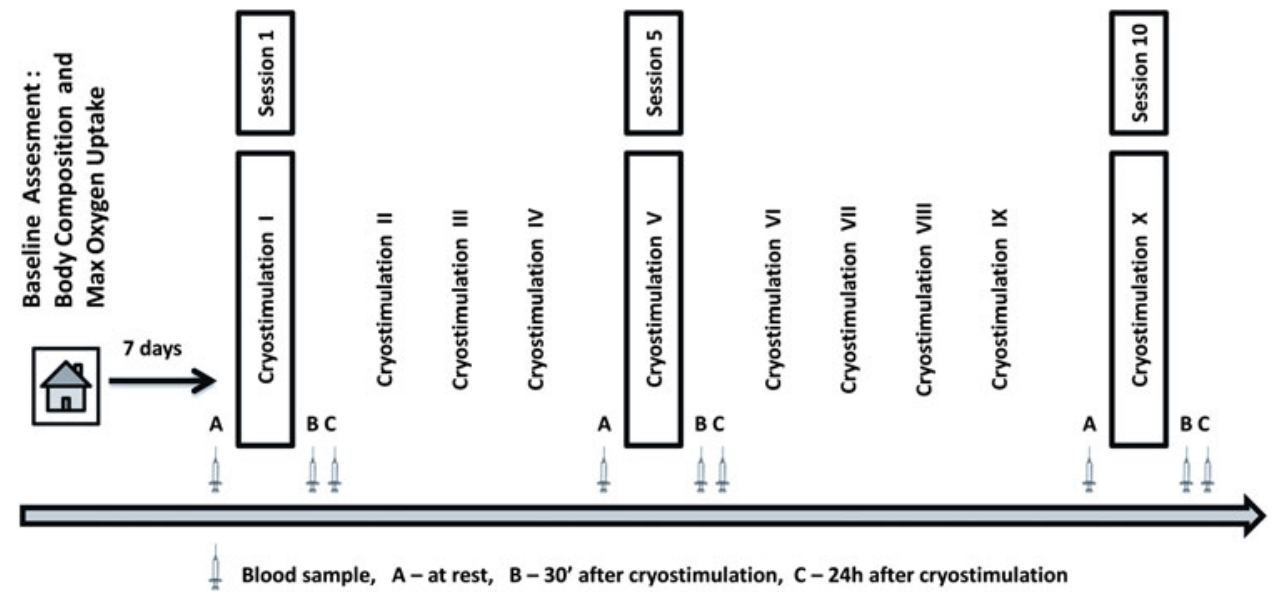

composition analyser (In Body 720; Biospace Analyzer, Korea). This analyser accurately measures the amount of body water and body composition, including fat mass, free fat mass, skeletal muscle mass and soft lean mass. Additionally, the visceral fat area was determined and expressed in $\mathrm{cm}^{2}$. Precision of the repeated measurements was expressed as the coefficient of variation, which on average was $0.6 \%$ for fat mass percentage [32]. The measurements were taken $1 \mathrm{~h}$ before breakfast. The participants had emptied their bladders and bowels prior to the assessment. During the measurement, the participants wore only briefs and remained barefoot. The body composition analysis was repeated 1 day after the procedure of 10 sessions of whole body cryostimulation.

\section{Cardiorespiratory fitness measurement}

To determine $\mathrm{VO}_{2 \max }$, the participants performed a graded cycle ergometry test on an electromagnetically braked, cycle ergometer (ER 900; Jaeger/Viasys Health Care, Germany). The participants were allowed a 5-min warm up at an intensity of $1.5 \mathrm{~W} \mathrm{~kg}^{-1}$, with a pedalling cadence of $60 \mathrm{rpm}$. Immediately following the warm-up, the participants began $\mathrm{VO}_{2 \max }$ testing by cycling at a gradually increasing workload by $25 \mathrm{~W} \mathrm{~min}{ }^{-1}$ until the participant reached the point of volitional exhaustion [33, 34]. The recovery was passive, with the participant in a seated position. Breath-by-breath pulmonary gas exchange was measured throughout the $\mathrm{VO}_{2 \max }$ test; the $\mathrm{O}_{2}$ and $\mathrm{CO}_{2}$ analysers were calibrated prior to each test using standard gases of known concentrations in accordance with manufacturer guidelines.

\section{Whole-body cryostimulation}

All the participants were subjected to a series of coldness exposures (once a day at 0930 hours, 10 sessions per series) in a cryogenic chamber at the Pomeranian
Rheumatologic Centre in Sopot, Poland, conducted by highly qualified, medical staff. Each cryostimulation session lasted $3 \mathrm{~min}$ at a temperature of $-110{ }^{\circ} \mathrm{C}$. Entry into the cryo-chamber was preceded by a 20 - to 30 -s adaptation in the vestibule at a temperature of $-60{ }^{\circ} \mathrm{C}$. The subjects were dressed in shorts, socks, gloves, and a hat covering their auricles. Each exposure was preceded by a light breakfast between 0700 and 0730 hours according to the instructions given to the subjects.

\section{Blood analysis}

Blood samples were collected at 3 stages of the experiment: before and $24 \mathrm{~h}$ after the 1st, 5th and 10th coldness exposure. Additionally, based on data from a published study and changes in adipokines concentration after cold exposure [28], blood was collected $30 \mathrm{~min}$ after the selected exposures (Fig. 1). Blood samples were taken from the antecubital vein into the vacutainer tubes with EDTAK $_{2}$. Immediately after collection, the samples were divided into two portions. One portion was used for haematological measurements determined by conventional methods using a COULTER ${ }^{\circledR}$ LH 750 Hematology Analyzer (Beckman-Coulter, USA). The other portion was transferred to centrifuge tubes containing aprotinin (catalogue no. RK-APRO) from Phoenix Pharmaceuticals. The final concentration of aprotinin was 0.6 Trypsin Inhibitor Unit/1 $\mathrm{mL}$ of blood. The samples were centrifuged at 2,000 $\mathrm{g}$ for $10 \mathrm{~min}$ at $4{ }^{\circ} \mathrm{C}$. The separated plasma samples were frozen and kept at $-70{ }^{\circ} \mathrm{C}$ until later analysis. Plasma interleukins: IL-6, IL-10, and tumour necrosis factor alpha, $\mathrm{TNF} \alpha$, were determined by enzyme immunoassay methods using commercial kits (catalogue nos. HS600B, HS100C, HSTA00D; R\&D Systems, USA). An enzyme immunoassay method using commercially available kits from Phoenix Pharmaceuticals. was employed to determine the plasma visfatin C-terminus (catalogue no. EK-003-80) and adiponectin (catalogue no. EK-ADI-01), and kits from 
R\&D Systems were used to determine the levels of leptin (catalogue no. DLP00), leptin-soluble receptor (catalogue no. DOBR00) and resistin (catalogue no. DRSN00).

\section{Statistical calculations}

Statistical analysis was performed using Statistica 8.0 (StatSoft, USA) for Windows. A 2 (group) $\times 2$ (time) repeated measures analysis of variance (ANOVA) was used to determine the differences between the groups in the pre-, during and post-cryostimulation sessions. The level of significance was set at 0.05 for all analyses. Additionally, to elaborate on the differential significance between groups before and after whole-body cryostimulation, a method of multiple comparison (post hoc-HSD Tukey's) was applied. Statistical calculation presented in Table 1 were performed basing on data from all points of blood collection. Values of $p$ based on all blood collection samples are presented in Table 1. In the "Results" section, $p$ values refer to statistical differences of measurements for particular blood collections (post hoc). Furthermore, due to the small number of subjects, we also calculated the effect size (partial $\eta^{2}$ ) by ANOVA, ranging between 0 and 1 . Using Cohen's rule of thumb as well as the conversion table for eta squared, the interpretations of the partial $\eta^{2}$ value are unequivocal. However, the most restrictive interpretation method assigns values of partial $\eta^{2}$ to the effect size as follows: 0.1 constituted a small effect, 0.3 represented a medium effect, and values above 0.5 represented a large effect.

\section{Results}

All participants completed the study, with no adverse events being reported.

\section{Baseline data}

The basic anthropometric and physiological characteristics of the subjects are summarised in Table 2. All participants were categorised as obese, based on the average BMI of the HCF $\left(31.4 \pm 2.0 \mathrm{~kg} \mathrm{~m}^{-2}\right)$ and LCF group $(34.0 \pm 2.5$ $\mathrm{kg} \mathrm{m}^{-2}$ ). The absolute fat mass and percentage of fat tissue values exceeded the recommended ranges for subject age. Additionally, in both groups, an elevated amount of visceral fat area (VFA) was observed (Table 2). However, compared to the LCF group, the HCF group was characterised by significantly lower fat content, higher free fat mass (FFM) and skeletal muscle mass (SMM). All differences were statistically significant (Table 2).

The average values of maximal oxygen uptake were lower in the LCF group than the HCF group $(p<0.001)$.
The discrepancy between groups advanced when the relative maximal oxygen uptake was calculated per $\mathrm{kg}$ of SMM, confirming that the HCF group had higher cardiorespiratory fitness than the LCF group (Table 2).

Haematological parameter analysis revealed that all values were within the reference range; however, the LCF group displayed higher amounts of red blood cells $(p<0.01)$ and thrombocytes $(p<0.001)$ compared with the HCF group. Also, a discrepancy between groups in white blood cells was observed (Table 3 ). To estimate if our obese subjects experienced low-grade systemic inflammation, pro- and anti-inflammatory cytokines were measured. The immunological data showed that, compared with the LCF, the HCF group had lower concentrations of IL-6 $(p<0.05)$ and IL-10 $(p<0.05)$. Both groups presented elevated concentrations of the pro-inflammatory cytokine TNF $\alpha$, yet the ranges of groups' values indicated major diversification (Table 1). For the HCF group, the concentration of TNF $\alpha$ ranged from $\min 0.6 \mathrm{pg} \mathrm{mL}^{-1}$ to $\max 1.5 \mathrm{pg} \mathrm{mL}^{-1}$, whereas the LCF group varied from min $0.4 \mathrm{pg} \mathrm{mL}^{-1}$ to max. $4.0 \mathrm{pg} \mathrm{mL}^{-1}$ (Fig 2). In both groups, a significant, inverse correlation between TNF $\alpha$ and $\mathrm{VO}_{2 \max }$ was observed. The higher the maximal oxygen uptake, the lowest was the pro-inflammatory TNF $\alpha$ concentration (for HCF group $r=-77$ and for LCF $r=$ $-0.75, p<0.05)$.

Differences between groups were also recorded in concentrations of fat tissue hormones (adipokines). Subjects in the HCF group were characterised by lower concentrations of leptin $(p<0.001)$ and higher concentrations of leptin receptor (leptin sR) $(p<0.001)$ than the LCF group. Concentrations of the other pro-inflammatory adipokines, resistin and visfatin, were also lower in the HCF group ( $p<0.002$ and $p<0.05$, respectively) (Table 1). Regardless of an unclear role of visfatin in inflammation and discrepancies in the interpretation of its concentrations in relation to body mass components [2], visfatin values per $\mathrm{cm}^{2}$ visceral fat area were calculated, revealing that significant differences between groups were also present (Table 1).

Furthermore, significant differences in the anti-inflammatory adipokine adiponectin between groups were observed. The HCF group was characterised by a higher concentration compared with the LCF group. Differences between groups were statistically significant and post hoc analysis revealed $p<0.05$ for the baseline values.

In the first stage of the experiment (prior to applying cryostimulation procedure), we aimed to investigate whether the cardiorespiratory fitness and muscle mass affected adipokines concentration in obese men. Overall, greater values of $\mathrm{VO}_{2 \max }$ and muscle mass revealed lower resistin and higher leptin receptor concentration for all subjects (Table 4). Moreover, when the maximal oxygen uptake 


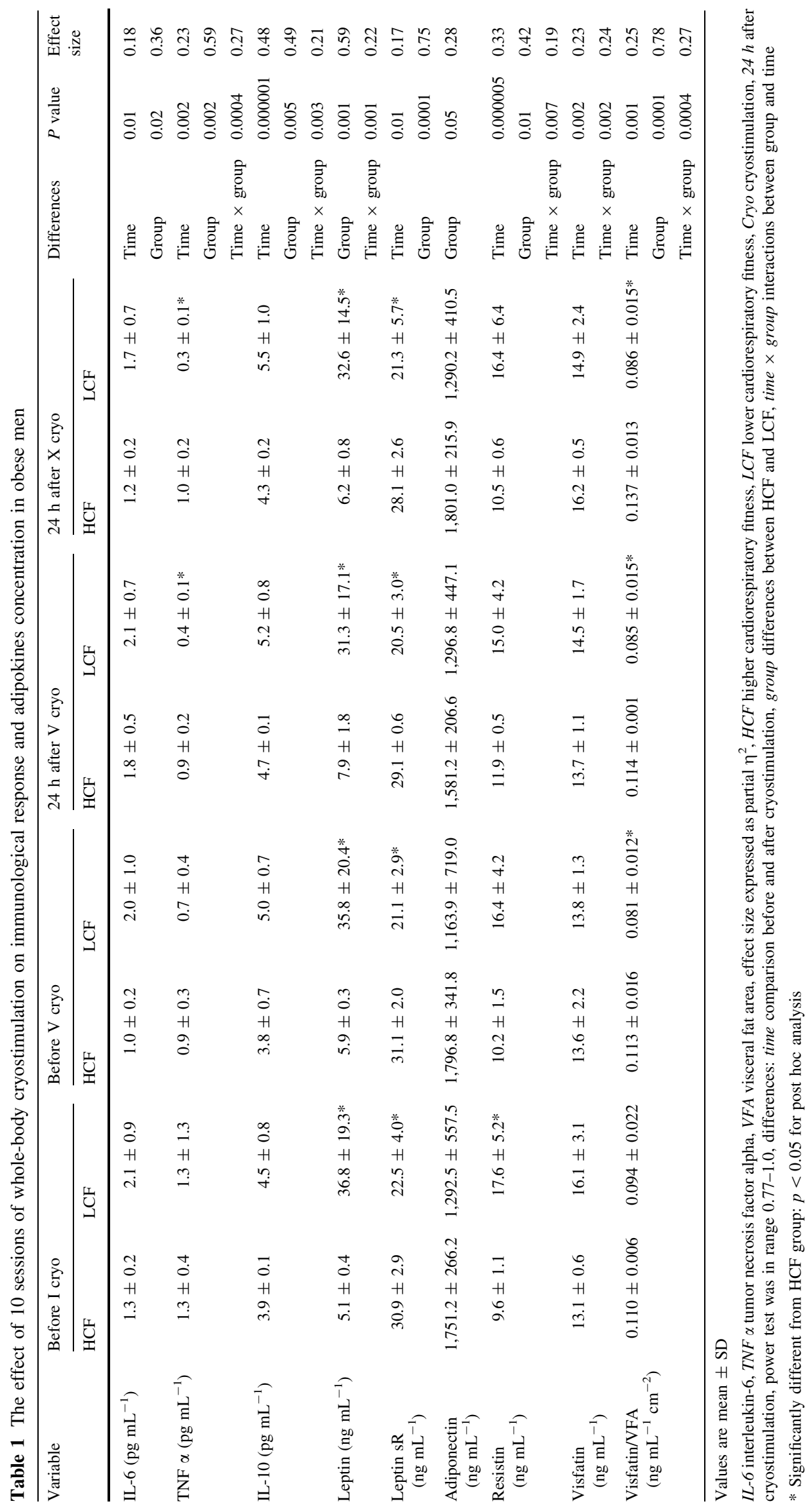


was calculated per skeletal muscle mass, it correlated with the concentrations of adipokines: negatively with leptin and positively with leptin sR (Table 4).

\section{Effect of 10 sessions of whole-body cryostimulation}

Immunological response and changes in adipokines concentrations after the whole body cryostimulation are presented in Table 1. According to our expectations, exposure to coldness did not cause any changes in body composition of our subjects (data not shown). Moreover, this treatment did not modify haematological parameters; thus, most initially observed differences between groups were maintained (Table 3). Nevertheless, 10 sessions of whole-body cryostimulation induced immunological alterations. The

Table 2 Anthropometric and physiological characteristics of participants

\begin{tabular}{lrcl}
\hline Variable & HCF group & LCF group & $P$ value \\
\hline FFM $(\mathrm{kg})$ & $76.5 \pm 2.7$ & $68.6 \pm 5.4$ & 0.004 \\
$\mathrm{SMM}(\mathrm{kg})$ & $43.8 \pm 1.6$ & $39.0 \pm 3.4$ & 0.005 \\
Fat $(\mathrm{kg})$ & $23.2 \pm 3.2$ & $38.9 \pm 8.2$ & 0.0007 \\
Fat $(\%)$ & $23.2 \pm 2.5$ & $35.8 \pm 4.2$ & 0.0002 \\
VFA $\left(\mathrm{cm}^{2}\right)$ & $122.6 \pm 9.5$ & $173.7 \pm 30.5$ & 0.001 \\
$\mathrm{VO}_{2 \max }\left(\mathrm{mL} \mathrm{kg}^{-1} \mathrm{~min}^{-1}\right)$ & $43.0 \pm 3.0$ & $25.7 \pm 2.0$ & 0.0002 \\
$\mathrm{VO}_{2 \max }\left(\mathrm{mL} \mathrm{kg}_{\text {SMM }}^{-1} \mathrm{~min}^{-1}\right)$ & $99.9 \pm 4.8$ & $71.1 \pm 9.6$ & 0.00004 \\
\hline
\end{tabular}

Values are mean $\pm \mathrm{SD}$

FFM free fat mass, SMM skeletal muscle mass, Fat fat mass, Fat \% percentage of body fat, $V F A$ visceral fat area, $V O_{2 \max }$ maximal oxygen uptake expressed in relatively values and per kg skeletal muscle mass, HCF $(n=7)$ higher cardiorespiratory fitness, LCF $(n=7)$ lower cardiorespiratory fitness ranges and tendencies of these changes were differentiated in both groups (Table 1). Values recorded in the LCF group $24 \mathrm{~h}$ after the last coldness exposure triggered decreases in the concentrations of IL- 6 and TNF $\alpha$ compared to the baseline. This descending trend of TNF $\alpha$ was maintained in the LCF group throughout the whole period of cryostimulation, with the trend being the most dynamic during the first 5 days of the series (Fig. 2). The drop in $\mathrm{TNF} \alpha$ concentration in the LCF group, recorded $24 \mathrm{~h}$ after the 5th session, was statistically significant compared to the baseline. The subsequent sessions of cryostimulation series enhanced this decrease. Following the coldness treatment, a decrease in TNF $\alpha$ was also observed in the HCF group, yet the drop was less pronounced (1.3 at baseline to $1.0 \mathrm{pg} \mathrm{mL}^{-1} 24 \mathrm{~h}$ after the last cryostimulation). At the same time, the concentration of IL-6 remained unchanged (Table 1).

Simultaneously, significant elevation of the antiinflammatory cytokine IL-10 was noted in both groups $(p<0.05$ in HCF and $p<0.001$ in LCF for values before and $24 \mathrm{~h}$ after the 10th session). The rise of IL-10 maintained in LCF group was maintained after the 5th and sustained $24 \mathrm{~h}$ after the last sessions. Repeated measures analysis of variance including all blood collection points indicated no significant differences (Table 1).

Furthermore, alternations in the concentrations of adipokines during and after whole-body cryostimulation were investigated. The concentration of leptin and leptin receptor did not change significantly in either group (Table 1). Moreover, exposures series did not trigger the elevation of adiponectin in either group. Nonetheless, positive correlations between SMM and adiponectin concentration recorded at baseline among all participants, reached statistical

Table 3 Hematological parameters of subjects at the baseline and $24 \mathrm{~h}$ after the last session of cryostimulation

\begin{tabular}{|c|c|c|c|c|c|c|}
\hline \multirow[t]{2}{*}{ Variable } & \multicolumn{2}{|c|}{ Before cryostimulation } & \multicolumn{2}{|c|}{$24 \mathrm{~h}$ after last cryostimulation } & \multirow[t]{2}{*}{$P$ value at baseline } & \multirow[t]{2}{*}{$P$ value $24 \mathrm{~h}$ after $\mathrm{XC}$} \\
\hline & $\mathrm{HCF}$ group & LCF group & $\mathrm{HCF}$ group & LCF group & & \\
\hline White blood cells $\left(10^{3} \mu \mathrm{L}\right)$ & $5.9 \pm 1.1$ & $7.6 \pm 1.0$ & $6.5 \pm 1.5$ & $7.5 \pm 0.5$ & 0.01 & 0.01 \\
\hline Neutrophiles (\%) & $55.2 \pm 10.4$ & $49.4 \pm 6.7$ & $47.0 \pm 7.1$ & $48.9 \pm 7.2$ & ns & ns \\
\hline Lymphocytes (\%) & $31.0 \pm 8.9$ & $39.7 \pm 6.1$ & $40.0 \pm 6.5$ & $39.8 \pm 6.7$ & ns & ns \\
\hline Monocytes (\%) & $10.0 \pm 1.9$ & $7.5 \pm 0.7$ & $8.0 \pm 0.7$ & $7.5 \pm 0.5$ & 0.007 & ns \\
\hline Eosinophiles (\%) & $3.2 \pm 1.0$ & $2.4 \pm 0.8$ & $3.0 \pm 1.5$ & $2.5 \pm 0.8$ & ns & ns \\
\hline Basophiles (\%) & $0.5 \pm 0.3$ & $1.1 \pm 0.3$ & $1.1 \pm 0.3$ & $1.1 \pm 0.2$ & 0.004 & ns \\
\hline Red blood cells $\left(10^{6} \mu \mathrm{L}\right)$ & $5.0 \pm 0.1$ & $5.4 \pm 0.3$ & $5.1 \pm 0.3$ & $5.4 \pm 0.4$ & 0.007 & 0.05 \\
\hline Hemoglobin $\left(\mathrm{g} \mathrm{dL}^{-1}\right)$ & $15.2 \pm 0.1$ & $15.9 \pm 0.9$ & $15.4 \pm 1.1$ & $15.8 \pm 0.9$ & ns & ns \\
\hline Hematocrit $(\%)$ & $43.6 \pm 0.8$ & $47.1 \pm 2.2$ & $44.0 \pm 2.0$ & $47.3 \pm 2.3$ & 0.002 & 0.01 \\
\hline Thrombocytes $\left(10^{3} \mu \mathrm{L}\right)$ & $209.0 \pm 17.5$ & $273.5 \pm 29.2$ & $259.0 \pm 35.5$ & $271.1 \pm 31.5$ & 0.0005 & $\mathrm{~ns}$ \\
\hline
\end{tabular}

Values are mean $\pm \mathrm{SD}$

$n s$ no significant statistical differences between groups, $H C F$ higher cardiorespiratory fitness, $L C F$ lower cardiorespiratory fitness, $X C$ last (10) whole body cryostimulation 
Fig. 2 Changes in TNF $\alpha$ concentration in HCF and LCF group during the whole exposure period, *significantly different from HCF group: $p<0.05$ for post hoc analysis

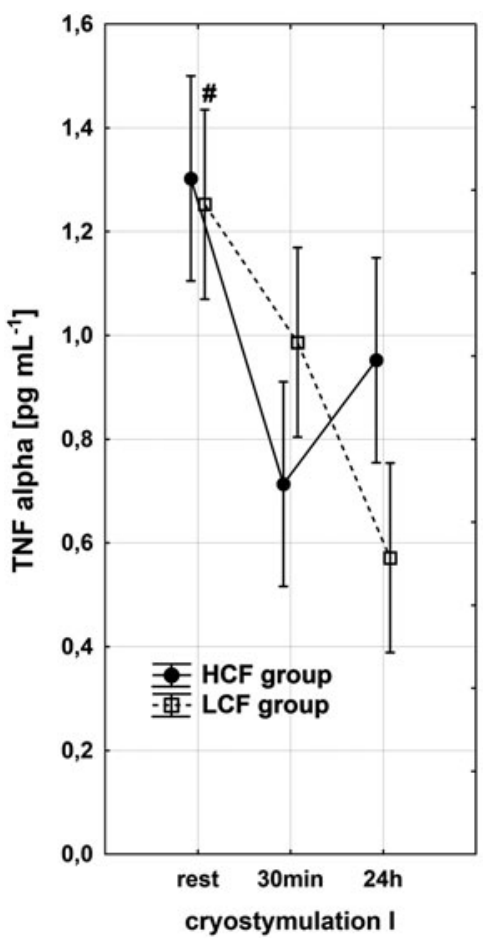

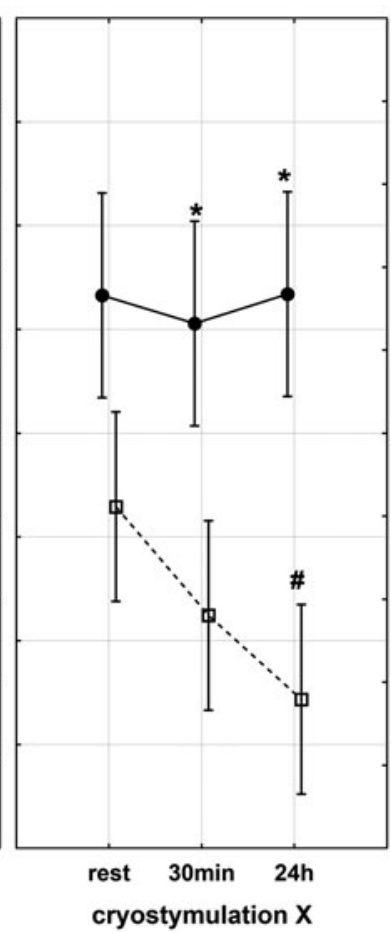

Table 4 The influence of cardiorespiratory fitness and body composition on adipokines concentration among all participants before and after the cryostimulation

\begin{tabular}{|c|c|c|c|c|c|c|c|c|c|c|}
\hline \multirow[t]{2}{*}{ Variable } & \multicolumn{2}{|c|}{ Leptin $\left(p g \mathrm{~mL}^{-1}\right)$} & \multicolumn{2}{|c|}{ Leptin $\mathrm{sR}\left(\mathrm{ng} \mathrm{mL} \mathrm{L}^{-1}\right)$} & \multicolumn{2}{|c|}{ Adiponectin $\left(\mathrm{ng} \mathrm{mL}^{-1}\right)$} & \multicolumn{2}{|c|}{ Resistin $\left(\mathrm{ng} \mathrm{mL} L^{-1}\right)$} & \multicolumn{2}{|c|}{ Visfatin $\left(\mathrm{ng} \mathrm{mL^{-1 }}\right)$} \\
\hline & $\mathrm{BC}$ & $24 \mathrm{~h} \mathrm{AC}$ & $\mathrm{BC}$ & $24 \mathrm{~h} \mathrm{AC}$ & $\mathrm{BC}$ & $24 \mathrm{~h} \mathrm{AC}$ & $\mathrm{BC}$ & $24 \mathrm{~h} \mathrm{AC}$ & $\mathrm{BC}$ & $24 \mathrm{~h} \mathrm{AC}$ \\
\hline SMM (kg) & -0.30 & -0.34 & $0.69 *$ & $0.62 *$ & 0.52 & $0.70 *$ & $-0.91 *$ & $-0.90 *$ & -0.11 & $0.54 *$ \\
\hline Fat $(\mathrm{kg})$ & $0.66^{*}$ & $0.71 *$ & $-0.60^{*}$ & $-0.63 *$ & -0.28 & -0.31 & 0.44 & 0.33 & $0.60 *$ & 0.10 \\
\hline Fat $(\%)$ & $0.65^{*}$ & $0.70^{*}$ & $-0.70^{*}$ & $-0.67 *$ & -0.40 & -0.48 & $0.66^{*}$ & $0.55^{*}$ & $0.54 *$ & -0.28 \\
\hline VFA $\left(\mathrm{cm}^{2}\right)$ & $0.64 *$ & $0.69 *$ & -0.49 & -0.48 & -0.24 & 0.20 & 0.37 & -0.30 & $0.60 *$ & -0.10 \\
\hline $\mathrm{VO}_{2 \max }\left(\mathrm{mL} \mathrm{kg}^{-1} \min ^{-1}\right)$ & $-0.80^{*}$ & $0.81^{*}$ & $0.70^{*}$ & 0.55 & 0.35 & 0.52 & $-0.67 *$ & -0.48 & $-0.60 *$ & 0.40 \\
\hline $\mathrm{VO}_{2 \max }\left(\mathrm{mL} \mathrm{kg}_{\mathrm{SMM}}^{-1} \min ^{-1}\right)$ & $-0.77 *$ & -0.70 & $0.70 *$ & 0.33 & 0.32 & 0.48 & $-0.61 *$ & -0.33 & -0.55 & 0.15 \\
\hline
\end{tabular}

Values are Pearson correlation

$B C$ before cryostimulation, $24 h$ AC after last cryostimulation, SMM skeletal muscle mass, Fat fat mass, Fat \% percentage of body fat, VFA visceral fat area, $V O_{2 \max }$ maximal oxygen uptake

* Values were significant at $p<0.05$

significance after the 10th session of cryostimulation (Table 4).

Variations of resistin and visfatin concentrations caused by cryostimulation followed divergent trends in both groups (Table 1). However, in both groups, changes resulted from the applied coldness exposures, as suggested by the effect size for group-time interaction of 19 and $21 \%$ for resistin and visfatin, respectively. After 10 sessions of whole-body cryostimulation, concentrations of resistin and visfatin in the HCF group increased compared to baseline by 9.4 and $23.4 \%$, respectively. Conversely, in the LCF group, the resistin and visfatin levels subsequently dropped by 6.8 and $7.4 \%$, respectively.
Unexpectedly, $24 \mathrm{~h}$ after the 10th session of cryostimulation, subjects characterised by higher skeletal muscle mass showed significantly higher concentrations of visfatin. The correlation between the maximal oxygen uptake and adipokines, observed at baseline in all participants, was maintained after the complete series of coldness exposures (Table 4).

\section{Discussion}

In the present study, we were able to demonstrate that whole-body cryostimulation is effective in reducing 
low-grade inflammation. The obtained data revealed that 10 sessions of cryostimulation caused a significant decrease in TNF $\alpha$ concentration. At baseline, subjects exhibited elevated concentrations of TNF $\alpha$, very likely due to high levels of fat tissue, especially in the visceral fat area. This suggests that participants may have been experiencing lowgrade systemic inflammation, which is consistent with previously presented results [35]. Decreasing, post-cryostimulation TNF $\alpha$ levels observed $24 \mathrm{~h}$ after the last exposure corresponded with the Hirvonen et al. [22] findings, who observed that 7-day whole-body cryostimulation effectively reduced the inflammation process in rheumatoid arthritis patients. Additionally, our study showed that cryostimulation-induced changes in TNF $\alpha$ concentrations were affected by cardiorespiratory fitness. In the LCF group, whole-body cryostimulation caused a 4.3-fold decrease in TNF $\alpha$ levels, whereas in the HCF group, the recorded drop was smaller, yet still significant. Although the anti-inflammatory effect of exercise has been well documented [8, 36], the HCF group's results strongly suggest that cryostimulation might have potentiated this impact of physical activity. At the same time, in the HCF group, the whole body cryostimulation enhanced the inversely correlation between $\mathrm{TNF} \alpha$ and cardiorespiratory fitness, which was noted at baseline. In our previous published study, this procedure has been shown to effectively reduce TNF $\alpha$ concentrations in overreached athletes [37]. Decreased values of TNF $\alpha$ may be particularly significant in obese individuals, not only with respect to an inflammatory state reduction but also in regulating and interfering with energy metabolism, especially lipid homeostasis [38].

Whole-body cryostimulation increases IL-6 concentrations in highly trained tennis players as well as in untrained non-obese men $[23,37]$. In contrast, in the present study, IL-6 decreased in the LCF group, yet in the HCF remained almost constant. It is worth noting that IL-6 values at baseline varied between groups; the concentration in the HCF group was lower than in the LCF group. Such results may be attributed to the higher level of physical activity demonstrated by the HCF subjects, which has been reported to reduce IL-6 levels $[9,39,40]$. These discrepancies in the effect of IL- 6 concentration after whole-body cryostimulation may result from distinct body compositions of the non-obese and our obese participants. Our study demonstrates that whole-body cryostimulation caused the pro-inflammatory $\mathrm{TNF} \alpha$ to decrease without being accompanied by IL- 6 concentration increases. This observation contrasts with previous studies [41], which had already reported that IL-6 inhibits TNF $\alpha$ production.

The last published study demonstrated that a single whole-body cryostimulation decreases muscle, core and skin temperatures [42]. The response to coldness exposure may change blood flow through the subcutaneous tissues, attenuating local hypoxic condition in hypertrophic fat cells. According to Ye and Gamble [43], the adipose tissue hypoxia may reflect a compensatory failure in the local vasculature system in response to obesity. Therefore, better blood flow may enhance oxygen supply and limit the production of reactive oxygen species and counteract inflammation. This is in agreement with the study by Miller and co-authors [24], who indicated that cryostimulation may reduce oxidative stress via a significant increase of the level of total antioxidant status, uric acid in plasma and activity of superoxide dismutase in erythrocytes.

The presence of systemic inflammation at baseline was also confirmed by the elevated, still in reference range, amount of white blood cells in the LCF group. The cold exposures did not significantly influence the haematological profile in our obese subjects. The results obtained contrast with the lately published study by Lombardi [44], who noted haematological changes in rugby players following cryostimulation. The discrepancy of the results may be conditioned by the application of a different cryostimulation procedure by Lombardi as well as differences in body composition of the participants between experiments.

Along with the drop of $\mathrm{TNF} \alpha$, we noted a significant, post-cryostimulation increase of the anti-inflammatory cytokine IL-10 in both groups. However, the baseline concentrations of IL-10 were significantly higher in the LCF than the HCF group. These data suggest that elevated concentrations of IL-10 may be a component of an enhanced defensive response to low-grade systemic inflammation. Initially, we hypothesised that exposure to a temperature of $-110{ }^{\circ} \mathrm{C}$ exerts an anti-inflammatory effect due to increased adiponectin production. Imbelaut and coauthors [28] indicated that a 120-min exposure to coldness $\left(4{ }^{\circ} \mathrm{C}\right)$ was accompanied by a significant increase in adiponectin levels in young, healthy men. Thus, we assumed that exposure to a considerably lower temperature of $-110{ }^{\circ} \mathrm{C}$ would induce a similar observable effect of increased adiponectin production. Nonetheless, our initial hypothesis was only partially confirmed by the obtained findings. First of all, 10 sessions of coldness exposure did not cause an elevation in adiponectin concentrations. The basic level of adiponectin in the HCF group was significantly higher than in the LCF, yet the recorded values were still lower than concentrations reported for lean individuals: 2,000-3,000 $\mathrm{ng} \mathrm{mL}^{-1}[2]$. These results are in agreement with previous studies, which noted hypoadiponectinemia in obese individuals $[45,46]$. The already mentioned hypoxic condition in excessive fat tissue induces the oxidative stress via activating $\mathrm{NADPH}$, deregulating adiponectin production [47]. Conditions of cryostimulation may have been sufficient to reduce inflammation; however, the applied number of sessions may have been insufficient to improve adiponectin concentration. Lubkowska and 
co-authors [48] revealed that the beneficial effect of wholebody cryostimulation depends on the number of applied sessions.

Interestingly, we observed a positive correlation between skeletal muscle mass and adiponectin. What is more, the significance of this correlation was strengthened after the series of cryostimulation. It might have resulted from a significant decrease of the pro-inflammatory cytokine TNF $\alpha$. It has been shown that TNF $\alpha$ suppresses the transcription of the adiponectin gene in adipocyte cells [49]. Moreover, previous studies have revealed that resistance training, known to increase muscle mass, have caused the plasma adiponectin concentration to rise [13].

As it has been consistently reported, obese individuals exhibit elevated levels of leptin $[2,50,51]$; hence, in this study, we attempted to examine the effect of whole-body cryostimulation on this adipokine. The applied protocol of coldness exposures did not affect the concentration of leptin; however, significant differences in leptin concentrations noted between the groups at baseline were sustained throughout the period of coldness treatment. As expected, compared to the LCF, the HCF group exhibited lower concentrations of circulating leptin and higher concentrations of leptin receptor, both within the recommended ranges for lean subjects [52]. Consequently, our data clearly indicate that the maximal oxygen uptake, expressed in $\mathrm{mL}$ per $\mathrm{kg}$ skeletal muscle mass, correlated negatively with leptin concentrations but positively with leptin receptor levels. These data also suggest that the amount of muscle mass and the metabolic capacity are crucial for regulating leptin levels.

In the LCF group, the elevated leptin levels were also accompanied by higher concentrations of visfatin-the adipocytokine associated with obesity and visceral fat $[7$, 53]. Visfatin was also elevated in the HCF group. Interestingly, although the HCF group had lower concentrations of visfatin than the LCF group, its visfatin levels before cryostimulation were twofold higher than values recorded for non-obese and trained rowers examined $\left(7.0 \mathrm{ng} \mathrm{mL}^{-1}\right)$ by Jurimae [54].

In the current study, at baseline, circulating visfatin levels correlated positively with IL-10 (not shown) and inversely with cardiorespiratory fitness in all participants. This was most likely due to the fact that visfatin may induce the expression of the anti-inflammatory cytokines, IL-10 and IL-1ra [55]. The 10 sessions of cryostimulation triggered changes in the visfatin concentration in both groups, causing an increase in the HCF group but a decrease in the LCF group. Previously, Haus et al. [56] observed a reduction in visfatin concentrations after 12 weeks of aerobic exercise training in older, obese individuals. The data gathered may be explained by the fact that, under cold conditions, shivering in the HCF group was intensified to a greater extent than in the LCF group due to their larger fat tissue content. Shivering can lead to enhanced visfatin synthesis by the skeletal muscles, which was noted to be the source of this cytokine $[57,58]$. These speculations might be confirmed by the positive correlation between skeletal muscle mass and visfatin concentration, which appeared after coldness exposure in all participants.

In addition, the changes in resistin concentration showed a similar tendency, such as the above-mentioned visfatin alternation. Resistin concentration, which was also twofold lower at baseline in the HCF group, dropped after exposure to coldness in LCF, whereas in the HCF group it unexpectedly increased. The elevated values at baseline in both groups confirmed previous observations that resistin links obesity and inflammation [59]. However, this adipokine is released mainly in human by macrophages $[60,61]$, not just adipocytes. Therefore, in this study, correlations between fat mass and resistin were scarcely observed. The decrease of resistin in the LCF group may have partially resulted from the reduction of the pro-inflammatory cytokines, IL-6 and TNF $\alpha$, which are known to increase reactive oxygen species production [62]. Recently, elevated resistin concentration has been associated with decreased indexes of oxidative stress; thus, it is possible that, in some conditions, its synthesis could be up-regulated in response to reactive oxygen species [63]. However, we have no explanation for why resistin was increased in the HCF group after cryostimulation.

\section{Conclusions}

In conclusion, whole-body cryostimulation application in obese individuals requires further investigation to address the following limitations of this study: a small number of subjects and a limited schedule of blood collection, which should have been adjusted to the work duties of participants. Further investigation should examine how long these induced changes are sustained. To our knowledge, this is the first study to report an anti-inflammatory effect of whole-body cryostimulation on the secretion of cytokines in obese men. Thus, our findings suggest that the designed procedure could be applied in obese individuals, yet its effectiveness also depends on cardiorespiratory fitness. Moreover, this procedure might support dietary modifications in weight loss through changes in adipokine concentration, which is involved in appetite regulation. Therefore, the whole-body cryostimulation can be a supplementary method (due to its low financial cost, it is also increasingly available: 10 exposures $=$ approx 120 Euro) involving exercise, and can possibly be used in some medical procedures and diets aimed to reduce systemic inflammation in obese individuals. 
Acknowledgments The authors would like to express their thanks to the medical staff of the hospital where the cold exposure took place, especially Aleksandra Kasińska and Piotr Krella, MD, for their help in conducting the research, and all of the participants for their engagement in the experiment. The experiment was funded by a knowledge grant of Gdansk University of Physical Education and Sport. There are no professional relationships between any of the authors and manufacturers of equipment utilised in this study.

Conflict of interest No conflict of interest occurs.

Open Access This article is distributed under the terms of the Creative Commons Attribution License which permits any use, distribution, and reproduction in any medium, provided the original author(s) and the source are credited.

\section{References}

1. von Ruesten A, Steffen A, Floegel A, van der AD, Masala G, Tjonneland A, Halkjaer J, Palli D, Wareham NJ, Loos RJ, Sorensen TI, Boeing H (2011) Trend in Obesity Prevalence in European Adult Cohort Populations during Follow-up since 1996 and Their Predictions to 2015. PLoS ONE 6: e27455

2. Tilg H, Moschen AR (2006) Adipocytokines: mediators linking adipose tissue, inflammation and immunity. Nat Rev Immunol 6:772-783

3. Garaulet M, Ordovas JM, Madrid JA (2010) The chronobiology, etiology and pathophysiology of obesity. Int J Obes (Lond) 34:1667-1683

4. Sood A (2010) Obesity, adipokines, and lung disease. J Appl Physiol 108:744-753

5. Kanda H, Tateya S, Tamori Y, Kotani K, Hiasa K, Kitazawa R, Kitazawa S, Miyachi H, Maeda S, Egashira K, Kasuga M (2006) MCP-1 contributes to macrophage infiltration into adipose tissue, insulin resistance, and hepatic steatosis in obesity. J Clin Invest 116:1494-1505

6. Khan SM, Hamnvik OP, Brinkoetter M, Mantzoros CS (2012) Leptin as a modulator of neuroendocrine function in humans. Yonsei Med J 53:671-679

7. Samara A, Pfister M, Marie B, Visvikis-Siest S (2008) Visfatin, low-grade inflammation and body mass index (BMI). Clin Endocrinol (Oxf) 69:568-574

8. Petersen AM, Pedersen BK (2005) The anti-inflammatory effect of exercise. J Appl Physiol 98:1154-1162

9. Pedersen BK (2012) Muscular interleukin-6 and its role as an energy sensor. Med Sci Sports Exerc 44:392-396

10. Bostrom P, Wu J, Jedrychowski MP, Korde A, Ye L, Lo JC, Rasbach KA, Bostrom EA, Choi JH, Long JZ, Kajimura S, Zingaretti MC, Vind BF, Tu H, Cinti S, Hojlund K, Gygi SP, Spiegelman BM (2012) A PGC1-alpha-dependent myokine that drives brown-fat-like development of white fat and thermogenesis. Nature 481:463-468

11. Ibanez J, Izquierdo M, Martinez-Labari C, Ortega F, Grijalba A, Forga L, Idoate F, Garcia-Unciti M, Fernandez-Real JM, Gorostiaga EM (2010) Resistance training improves cardiovascular risk factors in obese women despite a significative decrease in serum adiponectin levels. Obesity (Silver Spring) 18:535-541

12. Praet SF, Jonkers RA, Schep G, Stehouwer CD, Kuipers H, Keizer HA, van Loon LJ (2008) Long-standing, insulin-treated type 2 diabetes patients with complications respond well to shortterm resistance and interval exercise training. Eur J Endocrinol 158:163-172
13. Hopps E, Canino B, Caimi G (2011) Effects of exercise on inflammation markers in type 2 diabetic subjects. Acta Diabetol 48:183-189

14. Libardi CA, De Souza GV, Cavaglieri CR, Madruga VA, Chacon-Mikahil MP (2012) Effect of resistance, endurance, and concurrent training on TNF- $\alpha$, IL-6, and CRP. Med Sci Sports Exerc 44:50-56

15. Donges CE, Duffield R, Drinkwater EJ (2010) Effects of resistance or aerobic exercise training on interleukin-6, C-reactive protein, and body composition. Med Sci Sports Exerc 42:304313

16. Jenkins NT, Padilla J, Arce-Esquivel AA, Bayless DS, Martin JS, Leidy HJ, Booth FW, Rector RS, Laughlin MH (2012) Effects of endurance exercise training, Metformin, and their combination on adipose tissue leptin and IL-10 secretion in OLETF rats. J Appl Physiol

17. Nickel T, Hanssen H, Emslander I, Drexel V, Hertel G, SchmidtTrucksass A, Summo C, Sisic Z, Lambert M, Hoster E, Halle M, Weis M (2011) Immunomodulatory effects of aerobic training in obesity. Mediators Inflamm 2011:308965

18. Teixeira-Lemos E, Nunes S, Teixeira F, Reis F (2011) Regular physical exercise training assists in preventing type 2 diabetes development: focus on its antioxidant and anti-inflammatory properties. Cardiovasc Diabetol 10:12

19. Solomon TP, Sistrun SN, Krishnan RK, Del Aguila LF, Marchetti CM, O'Carroll SM, O'Leary VB, Kirwan JP (2008) Exercise and diet enhance fat oxidation and reduce insulin resistance in older obese adults. J Appl Physiol 104:1313-1319

20. Rao SR (2012) Inflammatory markers and bariatric surgery: a meta-analysis. Inflamm Res 61:789-807

21. Tam CS, Covington JD, Ravussin E, Redman LM (2012) Little evidence of systemic and adipose tissue inflammation in overweight individuals. Front Genet 3:58

22. Hirvonen HE, Mikkelsson MK, Kautiainen H, Pohjolainen TH, Leirisalo-Repo M (2006) Effectiveness of different cryotherapies on pain and disease activity in active rheumatoid arthritis. A randomized single blinded controlled trial. Clin Exp Rheumatol 24:295-301

23. Lubkowska A, Szygula Z, Klimek AJ, Torii M (2010) Do sessions of cryostimulation have influence on white blood cell count, level of IL-6 and total oxidative and antioxidative status in healthy men? Eur J Appl Physiol 109:67-72

24. Miller E, Markiewicz L, Saluk J, Majsterek I (2012) Effect of short-term cryostimulation on antioxidative status and its clinical applications in humans. Eur J Appl Physiol 112:1645-1652

25. Hausswirth C, Louis J, Bieuzen F, Pournot H, Fournier J, Filliard JR, Brisswalter J (2011) Effects of whole-body cryotherapy vs. far-infrared vs. passive modalities on recovery from exerciseinduced muscle damage in highly-trained runners. PLoS ONE 6:e27749

26. Pournot H, Bieuzen F, Louis J, Mounier R, Fillard JR, Barbiche E, Hausswirth C (2011) Time-course of changes in inflammatory response after whole-body cryotherapy multi exposures following severe exercise. PLoS ONE 6:e22748

27. Lubkowska A, Szygula Z, Chlubek D, Banfi G (2011) The effect of prolonged whole-body cryostimulation treatment with different amounts of sessions on chosen pro- and anti-inflammatory cytokines levels in healthy men. Scand J Clin Lab Invest 71:419-425

28. Imbeault P, Depault I, Haman F (2009) Cold exposure increases adiponectin levels in men. Metabolism 58:552-559

29. Puerta M, Abelenda M, Rocha M, Trayhurn P (2002) Effect of acute cold exposure on the expression of the adiponectin, resistin and leptin genes in rat white and brown adipose tissues. Horm Metab Res 34:629-634 
30. WHO (2000) Obesity: preventing and managing the global epidemic. Report of a WHO consultation. World Health Organ Tech Rep Ser 894:1-253

31. Astrand I (1960) Aerobic work capacity in men and women with special reference to age. Acta Physiol Scand Suppl 49:1-92

32. Volgyi E, Tylavsky FA, Lyytikainen A, Suominen H, Alen M, Cheng S (2008) Assessing body composition with DXA and bioimpedance: effects of obesity, physical activity, and age. Obesity (Silver Spring) 16:700-705

33. Heyward VH (2002) Assessing Cardiorespiratory Fitness, 4th edn. HumanKinetics, Champaign, pp 49-85

34. Katzmarzyk PT, Gagnon J, Leon AS, Skinner JS, Wilmore JH, Rao DC, Bouchard C (2001) Fitness, fatness, and estimated coronary heart disease risk: the HERITAGE Family Study. Med Sci Sports Exerc 33:585-590

35. Coppack SW (2001) Pro-inflammatory cytokines and adipose tissue. Proc Nutr Soc 60:349-356

36. Pedersen BK (2006) The anti-inflammatory effect of exercise: its role in diabetes and cardiovascular disease control. Essays Biochem 42:105-117

37. Ziemann E, Olek RA, Grzywacz T, Kujach S, Antosiewicz J, Garsztka T, Laskowski R (2012) Five-day whole-body cryostimulation, blood inflammatory markers and performance in highranking professional tennis players. J Athl Train 47:664-672

38. Chen X, Xun K, Chen L, Wang Y (2009) TNF- $\alpha$, a potent lipid metabolism regulator. Cell Biochem Funct 27:407-416

39. Febbraio MA, Pedersen BK (2005) Contraction-induced myokine production and release: is skeletal muscle an endocrine organ? Exerc Sport Sci Rev 33:114-119

40. Pedersen BK, Edward F (2009) Adolph distinguished lecture: muscle as an endocrine organ: IL-6 and other myokines. J Appl Physiol 107:1006-1014

41. Keller C, Steensberg A, Pilegaard H, Osada T, Saltin B, Pedersen BK, Neufer PD (2001) Transcriptional activation of the IL-6 gene in human contracting skeletal muscle: influence of muscle glycogen content. FASEB J 15:2748-2750

42. Costello JT, Culligan K, Selfe J, Donnelly AE (2012) Muscle, skin and core temperature after $-110{ }^{\circ} \mathrm{C}$ cold air and $8{ }^{\circ} \mathrm{C}$ water treatment. PLoS ONE 7:e48190

43. Ye J, Gimble JM (2011) Regulation of stem cell differentiation in adipose tissue by chronic inflammation. Clin Exp Pharmacol Physiol 38:872-878

44. Lombardi G, Lanteri P, Porcelli S, Mauri C, Colombini A, Grasso D, Zani V, Bonomi FG, Melegati G, Banfi G (2013) Hematological profile and marital status in rugby players during whole body cryostimulation. PLoS ONE 8:e55803

45. Kumada M, Kihara S, Sumitsuji S, Kawamoto T, Matsumoto S, Ouchi N, Arita Y, Okamoto Y, Shimomura I, Hiraoka H, Nakamura T, Funahashi T, Matsuzawa Y (2003) Association of hypoadiponectinemia with coronary artery disease in men. Arterioscler Thromb Vasc Biol 23:85-89

46. Han SH, Quon MJ, Kim JA, Koh KK (2007) Adiponectin and cardiovascular disease: response to therapeutic interventions. J Am Coll Cardiol 49:531-538

47. Furukawa S, Fujita T, Shimabukuro M, Iwaki M, Yamada Y, Nakajima Y, Nakayama O, Makishima M, Matsuda M, Shimomura I (2004) Increased oxidative stress in obesity and its impact on metabolic syndrome. J Clin Invest 114:1752-1761

48. Lubkowska A, Dolegowska B, Szygula Z (2012) Whole-body cryostimulation-potential beneficial treatment for improving antioxidant capacity in healthy men-significance of the number of sessions. PLoS ONE 7:e46352

49. Maeda N, Shimomura I, Kishida K, Nishizawa H, Matsuda M, Nagaretani H, Furuyama N, Kondo H, Takahashi M, Arita Y, Komuro R, Ouchi N, Kihara S, Tochino Y, Okutomi K, Horie M, Takeda S, Aoyama T, Funahashi T, Matsuzawa Y (2002) Dietinduced insulin resistance in mice lacking adiponectin/ACRP30. Nat Med 8:731-737

50. Iikuni N, Lam QL, Lu L, Matarese G, La Cava A (2008) Leptin and inflammation. Curr Immunol Rev 4:70-79

51. Lam QL, Lu L (2007) Role of leptin in immunity. Cell Mol Immunol 4:1-13

52. Sinha MK, Opentanova I, Ohannesian JP, Kolaczynski JW, Heiman ML, Hale J, Becker GW, Bowsher RR, Stephens TW, Caro JF (1996) Evidence of free and bound leptin in human circulation. Studies in lean and obese subjects and during shortterm fasting. J Clin Invest 98:1277-1282

53. Sandeep S, Velmurugan K, Deepa R, Mohan V (2007) Serum visfatin in relation to visceral fat, obesity, and type 2 diabetes mellitus in Asian Indians. Metabolism 56:565-570

54. Jurimae J, Ramson R, Maestu J, Purge P, Jurimae T, Arciero PJ, von Duvillard SP (2009) Plasma visfatin and ghrelin response to prolonged sculling in competitive male rowers. Med Sci Sports Exerc 41:137-143

55. Tilg H, Moschen AR (2008) Role of adiponectin and PBEF/ visfatin as regulators of inflammation: involvement in obesityassociated diseases. Clin Sci (Lond) 114:275-288

56. Haus JM, Solomon TP, Marchetti CM, O'Leary VB, Brooks LM, Gonzalez F, Kirwan JP (2009) Decreased visfatin after exercise training correlates with improved glucose tolerance. Med Sci Sports Exerc 41:1255-1260

57. Frydelund-Larsen L, Akerstrom T, Nielsen S, Keller P, Keller C, Pedersen BK (2007) Visfatin mRNA expression in human subcutaneous adipose tissue is regulated by exercise. Am J Physiol Endocrinol Metab 292:E24-E31

58. Costford SR, Bajpeyi S, Pasarica M, Albarado DC, Thomas SC, Xie H, Church TS, Jubrias SA, Conley KE, Smith SR (2010) Skeletal muscle NAMPT is induced by exercise in humans. Am J Physiol Endocrinol Metab 298:E117-E126

59. Janowska J, Zahorska-Markiewicz B, Olszanecka-Glinianowicz M (2006) Relationship between serum resistin concentration and proinflammatory cytokines in obese women with impaired and normal glucose tolerance. Metabolism 55:1495-1499

60. Nagaev I, Smith U (2001) Insulin resistance and type 2 diabetes are not related to resistin expression in human fat cells or skeletal muscle. Biochem Biophys Res Commun 285:561-564

61. Savage DB, Sewter CP, Klenk ES, Segal DG, Vidal-Puig A, Considine RV, O'Rahilly S (2001) Resistin/Fizz3 expression in relation to obesity and peroxisome proliferators-activated receptor-gamma action in humans. Diabetes 50:2199-2202

62. Antosiewicz J, Ziolkowski W, Kaczor JJ, Herman-Antosiewicz A (2007) Tumor necrosis factor-alpha-induced reactive oxygen species formation is mediated by JNK1-dependent Ferritin degradation and elevation of labile iron pool. Free Radic Biol Med 43:265-270

63. Bo S, Gambino R, Pagani A, Guidi S, Gentile L, Cassader M, Pagano GF (2005) Relationships between human serum resistin, inflammatory markers and insulin resistance. Int J Obes (Lond) 29:1315-1320 